\title{
Starch/Polyester Films: Simultaneous Optimisation of the Properties for the Production of Biodegradable Plastic Bags
}

\author{
J. B. Olivato, M. V. E. Grossmann, A. P. Bilck, F. Yamashita \\ Departamento de Ciência e Tecnologia de Alimentos, Brasil \\ L. M. Oliveira \\ Centro de Pesquisa e Desenvolvimento de Embalagens, Centro de Tecnologia em Embalagens, Brasil
}

\begin{abstract}
Blends of starch/polyester have been of great interest in the development of biodegradable packaging. A method based on multiple responses optimisation (Desirability) was used to evaluate the properties of tensile strength, perforation force, elongation and seal strength of cassava starch/poly(butylene adipate-co-terephthalate) (PBAT) blown films produced via a one-step reactive extrusion using tartaric acid (TA) as a compatibiliser. Maximum results for all the properties were set as more desirable, with an optimal formulation being obtained which contained (55:45) starch/PBAT (88.2 wt. (\%)), glycerol (11.0 wt. (\%)) and TA (0.8 wt. (\%)). Biodegradable plastic bags were produced using the film with this formulation, and analysed according to the standard method of the Associação Brasileira de Normas Técnicas (ABNT). The bags exhibited a $45 \%$ failure rate in free-falling dart impact tests, a $10 \%$ of failure rate in dynamic load tests and no failure in static load tests. These results meet the specifications set by the standard. Thus, the biodegradable plastic bags fabricated with an optimised formulation could be useful as an alternative to those made from non-biodegradable materials if the nominal capacity declared for this material is considered.
\end{abstract}

Keywords: Starch/PBAT blends, tartaric acid, extrusion, desirability, biodegradable bags.

\section{Introduction}

The global consumption of plastics in 2002 was of 120 million tons, and Brazil was responsible by 4200 tons of this total. The packaging sector is responsible for the greatest utilisation of plastics, which corresponds to more than a third of the Brazilian consumption ${ }^{[1]}$. The plastic bags provided by markets, which are resistant and convenient, represent a large portion of all the plastic bags produced and supplied to consumers ${ }^{[2]}$. These data show the inherent need for the development of alternatives for the substitution, or at least the partial substitution, of this type of packaging with another material that is ecologically favourable and that exhibits properties similar to those of synthetic plastics.

Starch is a polysaccharide formed by units of d-glucose and two different macromolecules: amylose, which possesses an essential linear structure, with a few branches, and amylopectin, which possesses a highly branched structure ${ }^{[3]}$. In the presence of plasticisers, at high temperature and under shear, starch tends to melt and flow, which enables its use in injection and blown film extrusion equipment. This property makes starch similar to most of the synthetic conventional polymers, with the additional advantages of being abundant, renewable, inexpensive and biodegradable $\mathrm{e}^{[4-6]}$.

Thermoplastic starch (TPS) alone is not adequate for use in packaging because is fragile and sensitive to environmental conditions $^{[7]}$. To overcome this difficulty, several researchers have focused on the development of blends that contain TPS added to biodegradable polyesters, such as PBAT (poly(butylene adipate-co-terephthalate)) and PLA (polylactic acid) ${ }^{[8-10]}$. In these cases, the use of additives (compatibilisers) capable of acting at the interface and improving the adhesion between the polymeric chains is necessary. This adhesion is impaired by the differences between the hydrophilic starch and the hydrophobic polyester. In this context, tartaric acid (TA) can be added. TA is an organic acid naturally present in fruits, mostly in grapes, that can act as plasticiser or acidifier or can be used to promote esterification/transesterification reactions between polymers ${ }^{[11-13]}$.

Reactive extrusion is useful in the modification of the properties of starch and in the production of TPS blended with other materials. This process is industrially viable and continuous and offers the advantage of being a good mixing device, especially for high-viscosity systems such as TPS ${ }^{[4]}$. Films produced by blown extrusion are typically evaluated for their mechanical properties, including their tensile strength, elongation and perforation force.

Systems that provide a multiplicity of responses require data processing, with the aim of obtaining the best combination of factors that estimate the best possible combination of responses ${ }^{[14]}$. The technique of desirability represents a way to achieve this goal through the analysis of all data together, where each parameter is converted into a normalised function with a value of 0 (less desirable) to 1 (more desirable), according to the method proposed by Derringer and Suich ${ }^{[15]}$.

This work is aimed at the production of cassava starch/PBAT biodegradable films by a one-step reactive extrusion, where TA is added as a compatibiliser, and the analysis of the mechanical results using the technique of desirability. Additionally, the optimal conditions found using this technique were used to produce a blown film, which was characterised and used to produce plastic bags with properties similar to those made from synthetic plastics currently available in the market.

\section{Experimental}

\section{Materials}

Native cassava starch was supplied by Indemil (Paranavaí, $\mathrm{PR} /$ Brazil), and the polyester PBAT (poly(butylene adipate-coterephthalate)) was supplied by BASF (Ludwigshafen, Germany) 
Table 1. Concentration of the components in the formulations according to a mixture design.

\begin{tabular}{ccccccc}
\hline \multirow{2}{*}{ Samples } & \multicolumn{3}{c}{ Components (\%) } & \multicolumn{3}{c}{ Pseudo-components* } \\
\cline { 2 - 7 } & Starch + PBAT (55:45) & Glycerol & Tartaric acid & $\mathbf{x}_{1}$ & $\mathbf{x}_{2}$ & $\mathbf{x}_{3}$ \\
\hline S0 & 88.0 & 12.0 & 0.0 & 0.3 & 0.7 & 0.0 \\
S1 & 87.0 & 11.9 & 1.1 & 0.0 & 0.6 & 0.4 \\
S2 & 89.5 & 9.9 & 0.5 & 0.8 & 0.0 & 0.2 \\
S3 & 87.5 & 11.9 & 0.5 & 0.2 & 0.6 & 0.2 \\
S4 & 89.0 & 9.9 & 1.1 & 0.6 & 0.0 & 0.4 \\
S5 & 88.3 & 10.9 & 0.8 & 0.4 & 0.3 & 0.3 \\
\hline
\end{tabular}

*To calculate the pseudo-components' values, the equation $x_{i}=c_{i}-a / 1-\Sigma a_{i}$ was used, where $x_{1}=\operatorname{starch}+$ PBAT, $x_{2}=$ glycerol and $x_{3}=\operatorname{tartaric}$ acid; $c_{i}$ is the actual concentration; and $a_{i}$ is the lower limit of each component in the mixture design.

under the commercial name Ecoflex ${ }^{\circledR}$. Glycerol supplied by Dinâmica (Diadema, SP/Brazil) and TA supplied by Sigma-Aldrich (Steinheim, Germany) were also used.

\section{Methods}

\section{Experimental design}

To evaluate the influence of glycerol as a plasticiser and TA as a compatibiliser in starch/PBAT blends, a mixture design was proposed, as shown at Table 1, in which the third component of the ternary mixture is represented by starch + PBAT in a 55:45 (wt) proportion.

After a polynomial model was fit to the response, its simultaneous optimisation was conducted using the technique of Desirability according to the method described by Derringer and Suich $^{[15]}$, which parameters were defined as more desirable (1) and less desirable ( 0$)$ with base of the obtained results of the tested formulations (Table 2). The STATISTICA 7.0 software package (Statsoft, Tulsa/USA) was used to analyse data and plot the graphics of the properties of the films.

\section{Blown film extrusion}

Pellets were produced using a laboratory single-screw extruder (model EL-25, BGM, São Paulo, Brazil) with a screw diameter (D) of $25 \mathrm{~mm}$ and a screw length of $28 \mathrm{D}$ according the mixture design shown in Table 1. The barrel temperature profile was maintained at $100 / 120 / 120 / 120{ }^{\circ} \mathrm{C}$ from the feeding zone (zone 1) to the die zone (zone 4). The screw speed was $40 \mathrm{rpm}$, and a die with six $2 \mathrm{~mm}$ diameter holes was used. The pellets were subsequently re-extruded using the same extruder to obtain blown films with a barrel temperature profile of $100 / 120 / 120 / 130{ }^{\circ} \mathrm{C}$ and $130{ }^{\circ} \mathrm{C}$ for the $50 \mathrm{~mm}$ film-blowing die and a screw speed of $40 \mathrm{rpm}$. The feed rate was maintained to ensure that the screw operated at full load. The film thickness was controlled via the roll-speed control and the air flow and was maintained between 100 and $150 \mu \mathrm{m}$.

\section{Characterisation and mechanical analysis}

A model TA.XT2i texture analyser (Stable Micro Systems, Surrey/England) fitted with a $50 \mathrm{~kg}$ load cell was used to perform the tensile, seal and puncture tests on the films. The tensile tests were based on ASTM standard method D882-00 ${ }^{[16]}$. Ten samples of each formulation were cut in the longitudinal direction with a length of $50 \mathrm{~mm}$ and a width of $20 \mathrm{~mm}$ and were fit to the tensile grips. The crosshead speed was set at $0.8 \mathrm{~mm} / \mathrm{s}$, and the initial distance between the grips was $30 \mathrm{~mm}$. The tensile strength (MPa) and elongation at break $(\%)$ were determined.

The puncture tests were performed based on ASTM standard method F1306-90 ${ }^{[17]}$ with 10 samples of each formulation, which were fixed in an appropriate dispositive that allowed exposure of $35 \mathrm{~mm}$ of the sample. The perforation was realised using a cylindrical
Table 2. Maximum and minimum results obtained for the tested formulations used as reference in the simultaneous optimisation of the responses.

\begin{tabular}{ccc}
\hline Parameters & Higher limit & Lower limit \\
\hline Seal Strength (N) & $720.27(1)$ & $188.51(0)$ \\
Tensile Strength (MPa) & $6.81(1)$ & $2.65(0)$ \\
Elongation (\%) & $736.68(1)$ & $176.92(0)$ \\
Puncture Force (N) & $24.36(1)$ & $10.99(0)$ \\
\hline
\end{tabular}

Values in parentheses are the Desirability.

probe with a diameter of $3.0 \mathrm{~mm}$ and a speed of $0.4 \mathrm{~mm} / \mathrm{s}$, which was used to perpendicularly pierce the sample. The puncture force (N) was determined.

Seal strength $(\mathrm{N})$ was measured based on standard method ASTM F88-00 ${ }^{[18]}$ using 10 samples of each formulation that were $80 \mathrm{~mm}$ long and $25 \mathrm{~mm}$ wide. The samples were fixed into the tensile grips of the equipment, and the sealing area was positioned in the centre, perpendicular to the direction of traction. All the formulations were sealed in a hot-bar sealer, in which the temperature $\left(140^{\circ} \mathrm{C}\right)$ and the time ( 3 seconds) were kept constant. The sample was then submitted to traction with a crosshead speed of $1.0 \mathrm{~mm} / \mathrm{s}$ until the seal was disrupted. Before all of the tests, the samples were conditioned at $23 \pm 2{ }^{\circ} \mathrm{C}$ and $53 \pm 2 \% \mathrm{RH}$ for 48 hours.

The mechanical properties and seal strength were evaluated to obtain an optimised formulation according to the Desirability technique. Tensile strength, elongation, puncture force and seal strength were specified as the maximum levels desirable (Table 2). The formulation S5 (closer to the optimal formulation) was then used to produce plastic bags, which were submitted to free-falling dart impact tests, static load tests and dynamic load tests performed at the Centre for Research and Development of Packages (Centro de Pesquisa e Desenvolvimento de Embalagens, CETEA/ITAL), Campinas/SP/BR, according parameters specified in the ABNT NBR 14937:2010 standard $^{[19]}$.

To determine the bags' dynamic load strength, ten samples that contained $1 \mathrm{~kg}$ loads (declared as the nominal capacity) were tested in a vertical harmonic oscillation simulator operated with displacement amplitude of $100 \pm 2 \mathrm{~mm}$ and at a frequency of $1 \pm 0.1 \mathrm{~Hz}$ for $100 \pm 2$ seconds. The static load strength tests were performed with five samples that contained $1 \mathrm{~kg}$ and were suspended by their handles in a tubular support for $120 \pm 1$ minute. For both tests, the results are expressed as the presence or absence of failure (visual rupture with size $>10 \mathrm{~mm}$ ).

Twenty specimens with diameters of $125 \pm 2 \mathrm{~mm}$ were used to determine the material's falling dart strength, in which a dart with a polished surface and spherical tip diameter of $38 \pm 1 \mathrm{~mm}$ and a weight of $60.0 \pm 0.3 \mathrm{~g}$ was positioned $660 \mathrm{~mm}$ from the specimen such that it impacted the centre of the specimen during free fall. The results are expressed as the occurrence of a rupture of any size after the dart impact. 


\section{Scanning Electron Microscopy (SEM) Analysis}

An FEI model Quanta 200 scanning electron microscope (FEI, Tokyo, Japan) was used for the observations of the fractured surface of the film-blown samples. The samples were submerged in liquid nitrogen and then broken (cryogenic fracture). Before being coated with a gold layer, the samples were stored at $25^{\circ} \mathrm{C}$ in a desiccator with $\mathrm{CaCl}_{2}(\approx 0 \% \mathrm{RH})$ for 3 days. The coating was applied using a sputter coater (BAL-TEC SCD 050). Images were taken of the fractured surface at $800 \times$ and $1600 \times$ magnification.

\section{Results and Discussion}

\section{Analysis of the results and the simultaneous optimisation}

The diagram shown in Figure 1 presents the curves with the response observed for each variable analysed with the values of the other variables fixed. Each line shows the individual behaviour of the variables for each property analysed keeping constant the other variables. The results of all the properties used as reference in the Desirability technique are shown at Table 2.

The ability to seal a flexible film is one of the most important properties of the materials used in flexible packaging; it is essential to the integrity of the packaging and to guarantee the shelf-life of the packaged product ${ }^{[20]}$. The results of sealing strength varied from 190 to $720 \mathrm{~N}$ (Table 2). The glycerol content had little influence on this property, and a greater sealing strength to traction was observed when low concentrations of tartaric acid (TA) were used.
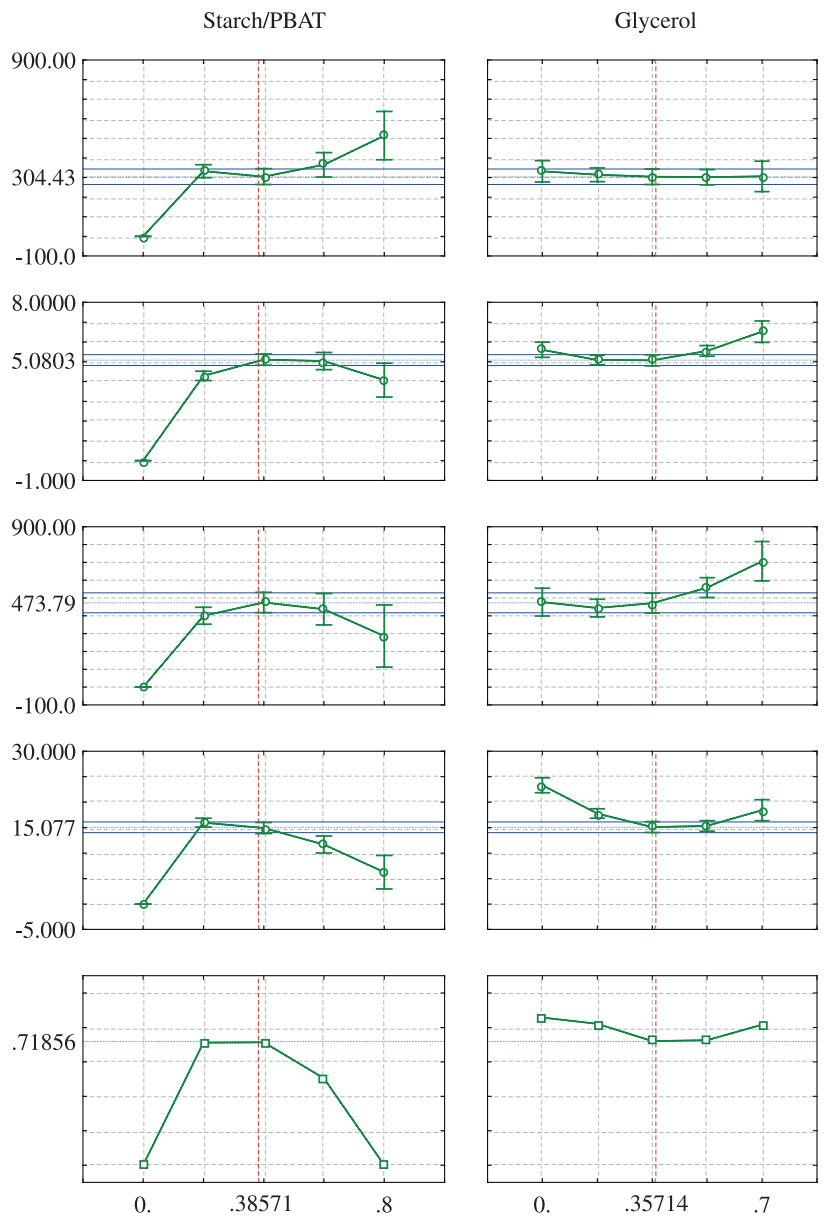

The puncture force is a quality parameter for materials used in the packaging of products with tips, edges and other protrusions that might damage the packaging ${ }^{[21]}$. The puncture force was observed to increase with the use of greater proportions of TA in the films, whereas for glycerol, the opposite effect was observed in which higher levels of glycerol resulted in films with a lower puncture force (Figure 1). The plasticiser action of glycerol, which is expected to reduce the intermolecular forces between the polymer chains, is responsible for this result, as also reported by other authors ${ }^{[22,23]}$. This plasticiser action also contributes to an increase in the elongation of the films because of the higher molecular mobility promoted by the addition of the plasticiser.

Tartaric acid, a dicarboxylic acid, induces acid hydrolysis of the starch chains, which reduces the molecular weight of the starch and consequently changes its melting temperature and viscosity, critical properties in the processing of thermoplastic starch. The inclusion of TA also results in more flexible films (higher elongation) ${ }^{[24]}$. Furthermore, the use of TA as an additive could allow the interaction of this component with the hydroxyl groups of the starch molecules, which promotes esterification/transesterification reactions that interconnect the polymer chains and improve the material's resistance, as observed in our previous works ${ }^{[25]}$.

Taking this into consideration, a comparison of the results shown in Figure 1 for the tensile strength and elongation of films, indicate that better results were achieved for both properties at intermediate concentrations, which produce more resistant and flexible films. These results show that, at these proportions, a balance exists between hydrolytic action and crosslinking promoted by the TA.
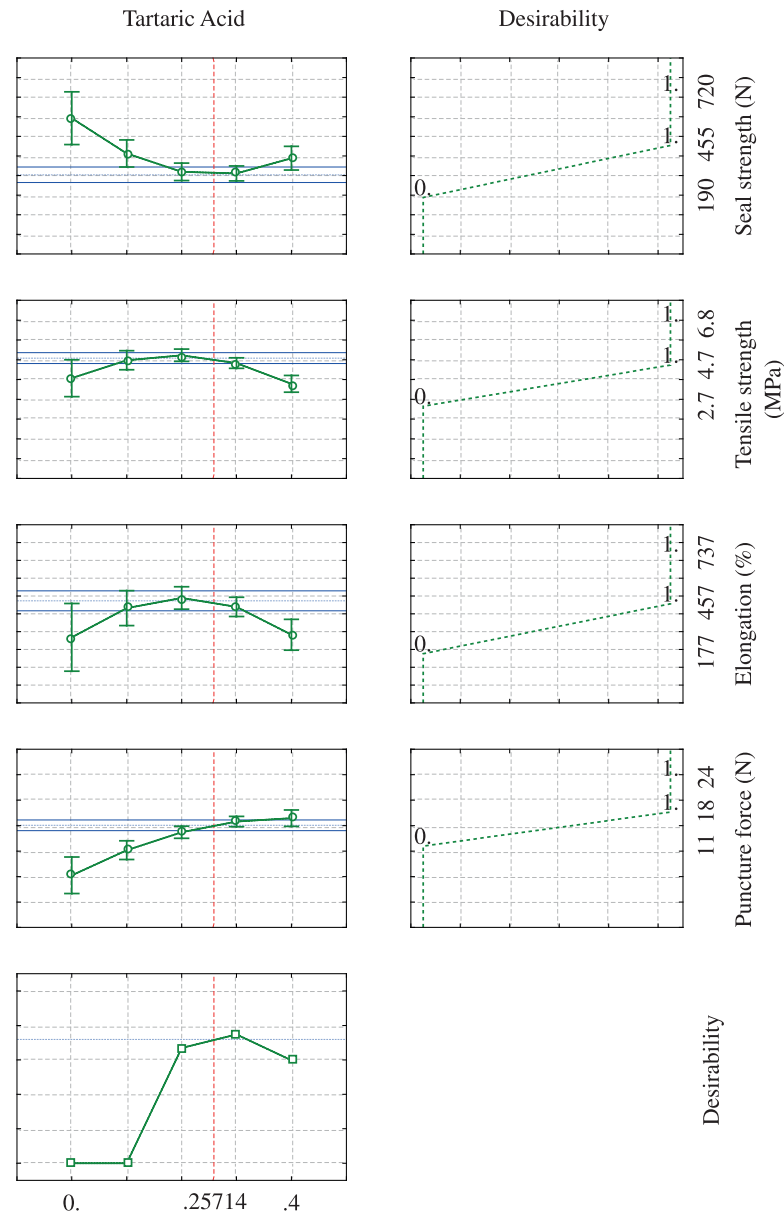

Figure 1. Desirability diagram based on the parameters of seal strength $(\mathrm{N})$, tensile strength $(\mathrm{MPa})$, elongation $(\%)$ and puncture force $(\mathrm{N})$. 


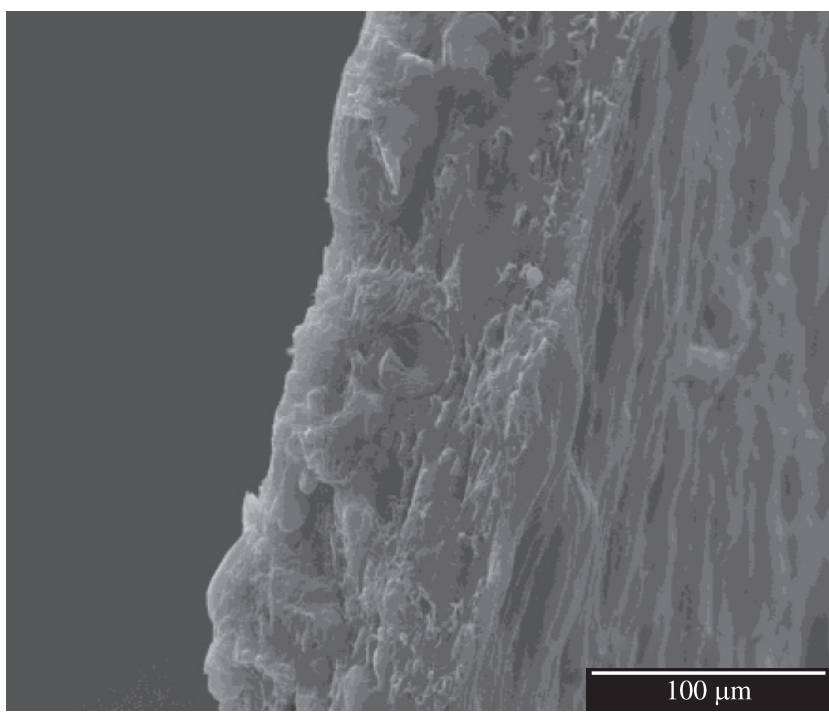

(a)

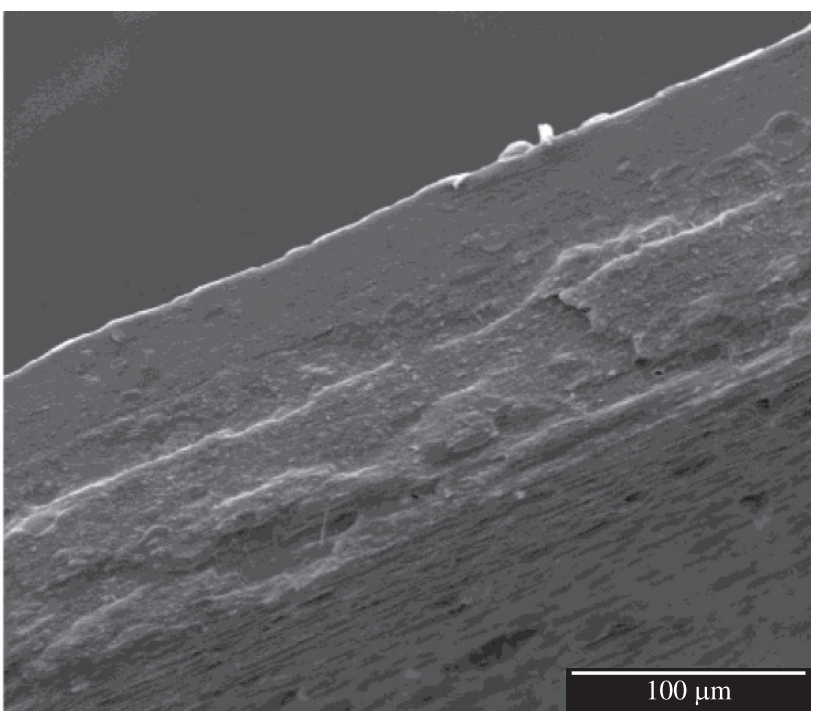

(b)

Figure 2. SEM images of fractured samples S0 (left) and S5 (right) at 800× magnification.

Thus, the compatibiliser action of TA in the films improves the interaction between the starch and hydrophobic PBAT, as evidenced by the SEM images in Figure 2.

The SEM image of the S0 sample (without TA) shows starch granules that have not been completely disrupted (Figure 3) and are distributed throughout the film polymer matrix, which has resulted in a non-homogeneous structure (Figure 2). With the addition of TA (sample S5), the disruption of starch granules is facilitated, and the compatibility between the polymer phases is improved, which has resulted in films with a continuous and more homogeneous matrix. Similar results were obtained by Miranda and Carvalho ${ }^{[26]}$, who compatibilised blends that contained thermoplastic starch and low-density polyethylene using citric acid, and by Olivato et al. ${ }^{[27]}$, who included citric acid in blends of starch/PBAT.

Based on the diagram shown in Figure 1, when the global Desirability (last line of the diagram) is considered, changes in both the TA concentration and the fraction that contains starch + PBAT influenced significantly the results of Desirability, and the use of intermediate concentrations of these components were observed to result in formulations with optimised properties. Thus, the Desirability function has resulted in values (pseudo-components data) that correspond to 0.386 for the mixture starch+PBAT (88.2\% w/w), 0.357 for glycerol $(11.0 \% \mathrm{w} / \mathrm{w})$ and 0.257 for TA $(0.8 \% \mathrm{w} / \mathrm{w})$. This composition therefore represents the most desirable formulation (expressed by the vertical line in the diagram).

\section{Evaluation of the properties of plastic bags made with the selected film}

The $\mathrm{S} 5$ formulation was closer to the theoretical values obtained by the Desirability function and was used for the production of films for biodegradable plastic bags (Figure 4). The results obtained for the analysis of these bags with respect to the free-falling dart impact strength, the static load strength and the dynamic load strength are shown in Table 3.

According to standard NBR 14937:2010 ${ }^{[19]}$, the fail tolerance is $50 \%$ in the free-falling dart impact strength test and $20 \%$ in the static load strength and dynamic load strength tests. Based on these tolerances, the developed sample meets the requirements set in the standard, once the bags produced with the optimised formulation (S5) exhibited a $45 \%$ failure rate in the free-falling dart impact

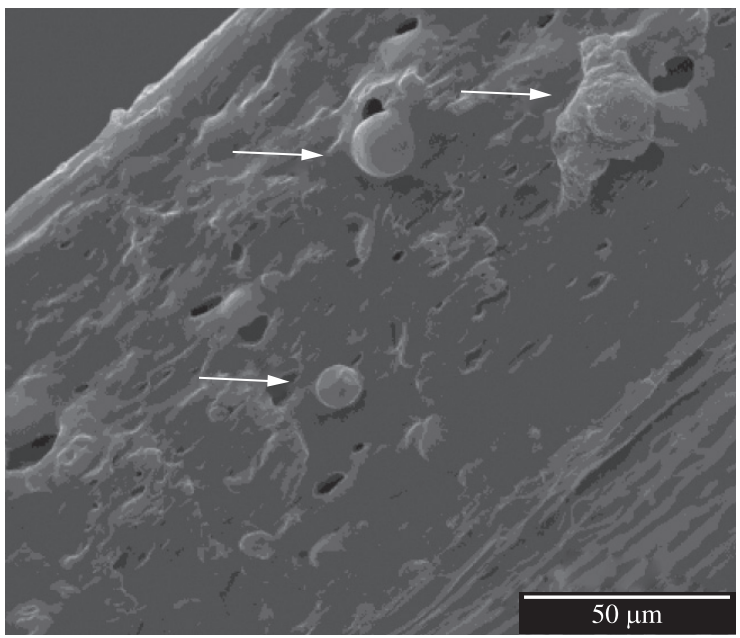

Figure 3. SEM image of fractured sample S0 at $1600 \times$ magnification. The arrows indicate granules of starch not completely disrupted.

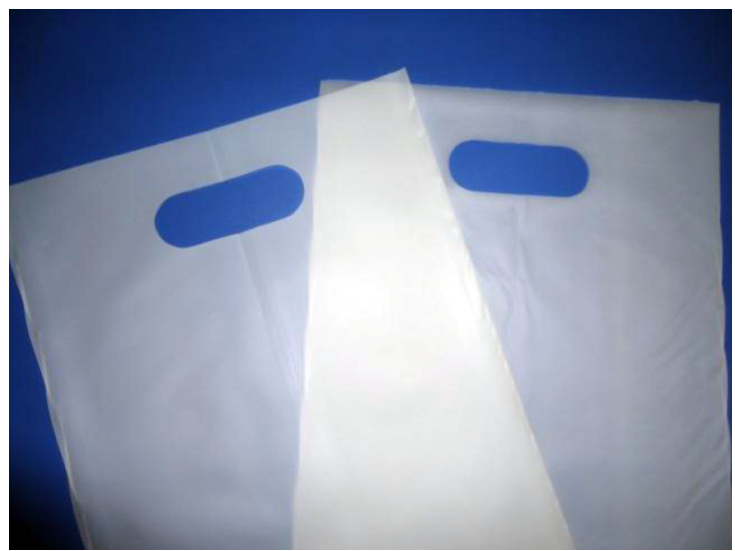

Figure 4. Biodegradable plastic bags developed using the S5 formulation.

strength test, a $10 \%$ failure rate in the dynamic load strength test and no failure in tests of static load strength. We therefore conclude that the developed bags are suitable for commercial use, taking into account the declared nominal capacity declared of this material. 
Table 3. Results of strength tests of plastic bags produced using the optimised formulation (S5).

\begin{tabular}{ccc}
\hline Test & Results \\
\hline Free-falling dart impact & Rupture (\%) & 45 \\
strength & Failure (\%) & 0 \\
Static load strength & Failure (\%) & 10 \\
Dynamic load strength & \\
\hline
\end{tabular}

The Supermarket Plastic Bags Analysis Report (Relatório de Análise em Sacolas Plásticas de Supermercados) was published by INMETRO on $24 / 06 / 2007^{[28]}$, in which samples of plastic bags available in 18 different markets in Brazil were evaluated in accordance with current legislation. Among the results for the strength tests that simulate common consumer usage of packing and loading store-bought goods, $75 \%$ of the brands analysed were considered not in accordance.

A comparison of these results to those obtained in the present work indicates that the starch-based bags are a viable and environmentally friendly alternative to synthetic packaging currently available on the market considering the nominal capacity declared for each material. However, more research is needed to reduce the sensitivity of starch-based materials to environmental conditions, which remains a challenge even with blends that contain polyester, which has represented a major advance in this direction.

\section{Conclusion}

The addition of TA improved the compatibility between the polymeric phases and resulted in blends with a more homogeneous structure and a continuous matrix, as evidenced by SEM images. Additionally, the TA contributed to the increase in the films puncture strength and, at intermediate concentrations, resulted in materials with a higher tensile strength and elongation. These improvements are possibly due to the role of TA in promoting crosslinking and acid hydrolysis of starch molecules, which together are responsible for such effects.

The Desirability method was effective in the combined optimisation of mechanical properties and heat-sealing strength and resulted in an optimised formulation that corresponded to a blend of starch/PBAT $(88.2 \% \mathrm{w} / \mathrm{w})$, glycerol $(11.0 \% \mathrm{w} / \mathrm{w})$ and TA $(0.8 \% \mathrm{w} / \mathrm{w})$.

The biodegradable plastic bags produced with formulation S5 (closest to the optimal formulation) and analysed according to the ABNT NBR 14937:2010 ${ }^{[19]}$ standard satisfied the requirements specified in this standard. Taking also into consideration the nominal specified load, these bags represent an alternative to non-biodegradable plastic bags currently sold for the packaging of low-weight products, which do not require a material of high mechanical strength.

\section{Acknowledgements}

The author thanks CNPQ, CAPES and the Araucaria Foundation (Fundação Araucária) for financial support given to this work.

\section{References}

1. Canevarolo Junior, S. V. - "Ciência dos Polímeros", Artliber, São Paulo (2010).

2. Sharp, A.; Hoj, S. \& Wheller, M. - J. Cons. Behav., 9, p.470 (2010). http://dx.doi.org/10.1002/cb.335

3. Avérous, L. - J. Macromol.Sci., C44, p.231 (2004). http://dx.doi. org/10.1081/MC-200029326

4. Moad, G. - Prog. Polym.Sci., 36, p.218 (2011). http://dx.doi. org/10.1016/j.progpolymsci.2010.11.002

5. Matta Junior, M. D.; Sarmento, S. B. S.; Sarantópoulos, C. I. G. L. \& Zocchi, S. S. - Polímeros, 21, p.67 (2011).

6. Yu, J.; Wang, N. \& Ma, X. - Starch/Starke, 57, p.494 (2005).
7. Kalambur, S. \& Rizvi, S. S. H. - J. Plast. Film Sheet., 22, p.39 (2006). http://dx.doi.org/10.1177/8756087906062729

8. Olivato, J. B.; Grossmann, M. V. E.; Yamashita, F.; Eiras, D. \& Pessan, L. A. - Carbohyd. Polym., 87, p.2614 (2012). http://dx.doi. org/10.1016/j.carbpol.2011.11.035

9. Wang, N.; Yu, J. \& Ma, X. - Polym. Int., 56, p.1440 (2007). http:// dx.doi.org/10.1002/pi.2302

10. Raquéz, J. M.; Nabar, Y.; Srinivasan, M.; Shin, B. Y.; Narayan, R. \& Dubois, P. - Carbohy. Polym., 74, p.159 (2008).

11. Eswaranandam, S.; Hettiarachchy, N. S. \& Meullenet, J. F. - J. Food Sci., 71, p.307 (2006). http://dx.doi.org/10.1111/j.1365-2621.2006. tb15658.x

12. Ren, J.; Fu, H.; Ren, T. \& Yuan, W. - Carbohyd. Polym., 77, p.576 (2009). http://dx.doi.org/10.1016/j.carbpol.2009.01.024

13. Yoon, S.; Chough, S. \& Park, H. - J. Appl. Polym. Sci., 100, p.3733 (2006). http://dx.doi.org/10.1002/app.23303

14. Carneiro, R. J.; Silva, R. S. S. F.; Borsato, D. \& Bona, E. - Semin. Cienc. Agrar., 26, p.353 (2005).

15. Derringer, G. \& Suich, R. - J. Qual. Tech., 12, p.214 (1980).

16. American Society for Testing and Materials - ASTM. - "D882-00: Standard test methods for tensile properties of thin plastic sheeting", Philadelphia (2001).

17. American Society for Testing and Materials - ASTM. - "F1306-90: Standard test method for slow rate penetration resistance of flexible barrier films and laminates", Philadelphia (2002).

18. American Society for Testing and Materials - ASTM. - "F88-00: Standard test method for seal strength of flexible barrier materials", Philadelphia (2001).

19. Associação Brasileira de Normas Técnicas-ABNT. "NBR 14937:2010: Sacolas plásticas tipo camiseta - Requisitos e métodos de ensaio", Rio de Janeiro (2010).

20. Oliveira, L. M.; Sarantópoulos, C. I. G. L.; Cunha, D. G. \& Lemos, A. B. - Polímeros, 16, p.202 (2006). http://dx.doi.org/10.1590/S010414282006000300009

21. Sarantópoulos, C. I. G. L.; Oliveira, L. M.; Padula, M.; Coltro, L.; Alves, R. M. V. \& Garcia, E. E. C. - "Embalagens Plásticas Flexíveis: Principais Polímeros e Avaliação de Propriedades", CETEA/ ITAL,Campinas (2002).

22. Parra, D. F.; Tadini, C. C.; Ponce, P. \& Lugão, A. B. - Carbohyd.

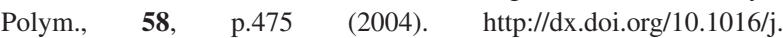
carbpol.2004.08.021

23. Cuq, B.; Gontard, N.; Cuq, J. L. \& Guilbert, S. - J. Agric. Food Chem., 45, p.622 (1997). http://dx.doi.org/10.1021/jf960352i

24. Da Róz, A. L.; Zambon, M. D.; Curvelo, A. A. S. \& Carvalho, A. J. F. - Ind. Crops Prod., 33, p.152 (2011). http://dx.doi.org/10.1016/j. indcrop.2010.09.015

25. Olivato, J. B.; Grossmann, M. V. E.; Bilck, A. P.; Yamashita, F. - Carbohyd. Polym., 90, p.159 (2012). http://dx.doi.org/10.1016/j. carbpol.2012.05.009

26. Miranda, V. R. \& Carvalho, A. J. F. - Polímeros, 21, p.353 (2011). http://dx.doi.org/10.1590/S0104-14282011005000067

27. Olivato, J. B.; Grossmann, M. V. E.; Yamashita, F.; Nobrega, M. M.; Scapin, M. R. S.; Eiras, D. \& Pessan, L. A. - Int. J. Food Sci. Tech., 46, p.1934 (2011). http://dx.doi.org/10.1111/j.1365-2621.2011.02704.x

28. Instituto Nacional de Metrologia, Qualidade e Tecnologia - INMETRO. - "Programa de Análise de Produtos". Disponível em: <http://www.inmetro.gov.br/consumidor/ prodAnalisados.asp?texto $=\&$ ordem $=$ titulo $\&$ pagina $=6>$. Acesso: 05 mar. 2012.

Enviado: 25/04/12

Reenviado: $19 / 06 / 12$ Aceito: 02/08/12 